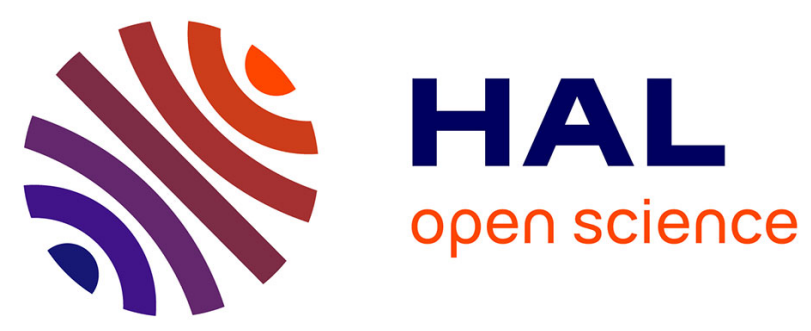

\title{
Mating frequency and genetic colony structure of the neotropical bumblebee Bombus wilmattae (Hymenoptera: Apidae)
}

Anett Huth-Schwarz, Adolfo León, Rémy Vandame, Robin Moritz, F. Kraus

\section{- To cite this version:}

Anett Huth-Schwarz, Adolfo León, Rémy Vandame, Robin Moritz, F. Kraus. Mating frequency and genetic colony structure of the neotropical bumblebee Bombus wilmattae (Hymenoptera: Apidae). Apidologie, 2011, 42 (4), pp.519-525. 10.1007/s13592-011-0038-4 . hal-01003571

\section{HAL Id: hal-01003571 \\ https://hal.science/hal-01003571}

Submitted on 1 Jan 2011

HAL is a multi-disciplinary open access archive for the deposit and dissemination of scientific research documents, whether they are published or not. The documents may come from teaching and research institutions in France or abroad, or from public or private research centers.
L'archive ouverte pluridisciplinaire HAL, est destinée au dépôt et à la diffusion de documents scientifiques de niveau recherche, publiés ou non, émanant des établissements d'enseignement et de recherche français ou étrangers, des laboratoires publics ou privés. 


\title{
Mating frequency and genetic colony structure of the neotropical bumblebee Bombus wilmattae (Hymenoptera: Apidae)
}

\author{
Anett Huth-Schwarz ${ }^{1}$, Adolfo León ${ }^{2}$, Rémy VAndame $^{3}$, Robin F. A. Moritz ${ }^{1}$, \\ F. Bernhard KRAUS ${ }^{1}$ \\ ${ }^{1}$ Institut für Biologie, Martin-Luther-Universität Halle-Wittenberg, Hoher Weg 4, 06099 Halle/Saale, Germany \\ ${ }^{2}$ Universidad de Ciencias y Artes de Chiapas, Tuxtla Gutiérrez, Chiapas, Mexico \\ ${ }^{3}$ El Colegio de la Frontera Sur, San Cristóbal de las Casas, Chiapas, Mexico
}

Received 20 May 2010 - Revised 14 September 2010 - Accepted 23 September 2010

\begin{abstract}
So far, nearly all studies concerning the mating frequency of bumblebees have been conducted with temperate species, showing that single mating seems to be the predominant pattern in bumblebees. Studies involving tropical species, however, are still scarce. Here, we determined the mating frequency of queens of the tropical bumblebee species, Bombus wilmattae by using microsatellite genotyping based on a sample of nine colonies from Chiapas, Southern Mexico. A total of 204 workers were genotyped with microsatellite markers to infer the queen genotype and the number of males with which each queen had mated. Two of the nine queens were doubly mated and seven singly mated. In the colonies with the double-mated queens, the distribution of the patrilines was not even, resulting in effective mating frequencies of 1.34 and 1.70, respectively, and an average relatedness of $g=0.58 \pm 0.06$.
\end{abstract}

Bombus wilmattae / bumblebees / eusocial Hymenoptera / mating frequency / microsatellites

\section{INTRODUCTION}

The mating frequency of queens in monogynous social hymenoptera determines the genetic colony structure and relatedness among the workers in the colony. Single mating results in a high intracolonial relatedness of $g=0.75$ (Crozier and Pamilo 1996), but each additional mating reduces the relatedness and increases intracolonial genetic variability. Because a high intracolonial relatedness is one of the base arguments for the evolution of sociality (Hamilton 1964a, b), polyandry has gained strong attention from researchers during the last decades (Moritz et al.

Corresponding author: A. Huth-Schwarz, anett.huth@zoologie.uni-halle.de Manuscript editor: Klaus Hartfelder
1995; Boomsma and Ratnieks 1996; SchmidHempel and Schmid-Hempel 2000; Foster and Ratnieks 2001; Payne et al. 2003). Multiple mating is, however, a rare trait and seems to be only common in more derived, highly eusocial Hymenoptera like honeybees, wasps, leafcutter ants or army ants (Strassmann 2001).

Bumblebees are characterised by an annual life cycle, and their colonies are headed by a single queen. Their colony size is rather small, ranging from about 50 to 2,000 individuals per colony (Sladen 1912; Plath 1934; Michener and LaBerge 1954). Studies on the mating frequencies of bumblebee queens in European, North American and Japanese Bombus species using microsatellite data revealed that the majority of species are singly mated $\left(N_{\text {species }}=72 \%\right)$. However, there are also occasional reports on 
polyandry of bumblebee queens. For example, queens of the temperate climate species Bombus hypnorum and Bombus mixtus have been shown to mate with up to six males (Estoup et al. 1995; Schmid-Hempel and Schmid-Hempel 2000; Paxton et al. 2001; Sauter et al. 2001; Payne et al. 2003; Takahashi et al. 2008a, b; Kokuvo et al. 2009). For tropical Bombus species, we are only aware of a study by Garofalo et al. (1986), who described the polyandrous mating behaviour of Bombus atratus with up to three matings per queen. However, since these observations were conducted under highly artificial experimental conditions in small containers it remains unclear whether this also occurs under natural conditions. Also for Bombus terrestris, behavioural observation of matings turned out to be less reliable than those based on genetic analyses (Röseler 1973; Estoup et al. 1995; Schmid-Hempel and Schmid-Hempel 2000).

One of the main hypotheses for the evolution of polyandry suggest that the increased withincolony genetic variability, caused by polyandry, results in an enhanced resistance towards parasites (Sherman et al. 1988; Keller and Reeve 1994; Mattila and Seeley 2007). Indeed, increased genetic variability, based on artificial insemination with sperm from multiple males, leads to lower parasite loads in B. terrestris, even though this is a single-mated species under natural conditions (Baer and Schmid-Hempel 1999). Since parasite pressure and parasite load exhibit a longitudinal cline and are markedly higher in tropical regions (Moller 1998; Nunn and Altizer 2005; Poulin and Rohde 1997; Cumming 2000; Poulin and Morand 2004), one might expect that tropical bumblebees are under greater parasitic pressure and queens should be more likely to exhibit polyandry compared to Bombus spp. from temperate climates.

In this study, we analysed the mating frequency and genetic colony structure of the neotropical bumblebee, B. wilmattae, using microsatellite analysis to obtain insight into the genetic colony structure and mating behaviour of tropical bumblebees on a reliable basis.

\section{MATERIALS AND METHODS}

\subsection{Species in focus}

The bumblebee species used in this study was B. (Pyrobombus) wilmattae, a species whose distribution is restricted to Chiapas, the southernmost state of Mexico and Guatemala. Although B. wilmattae was considered conspecific with the more widely distributed species Bombus ephippiatus by some authors (Labougle 1990; Williams 1998) a more recent study placed it closer to Bombus impatiens (Hines et al. 2006).

\subsection{Sampling}

B. wilmattae workers $(n=216)$ were sampled from nine colonies (C1-C9) from 2005 to 2008 in the vicinity of Unión Juárez, Chiapas, Mexico, close to the Guatemalan border $\left(15^{\circ} 3^{\prime} 52.31^{\prime \prime} \mathrm{N}, 92^{\circ} 4^{\prime} 52.32^{\prime \prime} \mathrm{W}\right.$ ) (Figure 1). Samples were collected as whole individuals or as single hind legs of workers (nonlethal sampling, Holehouse et al. 2003) and stored in $95 \%$ ethanol at $-20^{\circ} \mathrm{C}$ until DNA extraction.

\subsection{Molecular analysis}

DNA was extracted by using one leg of each individual following a Chelex-extraction protocol by Walsh et al. (1991). The sampled individuals were genotyped with five microsatellite markers (B100, B124, B126, B131, B132; Estoup et al. 1993, 1995). Additionally, four newly developed microsatellite markers (BTMS0065, BTMS0125, BTMS0126, BTMS0141; Stolle et al. 2009) were used for colony C9 (data not shown) to obtain sufficient resolution as the queen and the siring male shared identical alleles at two of the five initially used markers.

All individuals were genotyped following standard polymerase chain reaction (PCR) protocols and the obtained microsatellite fragments were scored in an automated DNA capillary sequencer (MegaBACE 1000 ) according to manufacturer's instructions.

\subsection{Data analysis}

The number of alleles $(A n)$ and the observed and the expected heterozygosities $\left(H_{\mathrm{o}}, H_{\mathrm{e}}\right)$ were assessed 


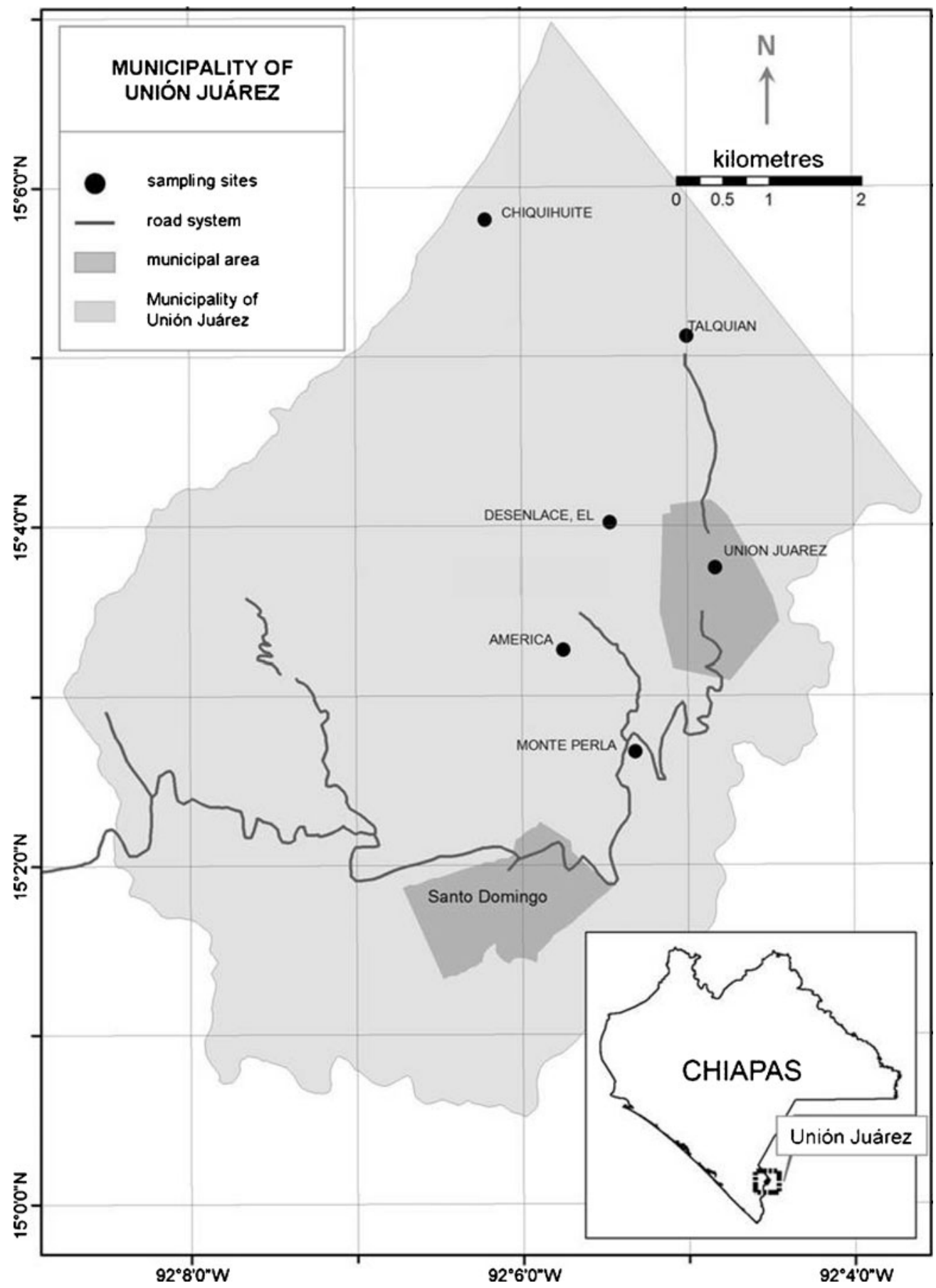

Figure 1. Sampling sites of the Bombus wilmattae colonies in the mountain region of the municipality Unión Juárez, Southern Mexico, near the Guatemalan border (Talquian C1, C2, C6, C7; Desenlace C3; Monte Perla C4; Chiquihutes C5, C9; América C8). 
with the Excel Microsatellite Toolkit (Park 2001). Deviations from Hardy-Weinberg equilibrium (HWE) and linkage equilibrium were tested using GENEPOP (version 1.2; Raymond and Rousset 1995).

For each colony, the queen genotype, the father genotypes and the observed number of matings were directly inferred from the genotypic data of the workers applying Mendelian rules. Additionally, MATESOFT 1.0 (Moilanen et al. 2004) was used for inferring the mating frequencies in each of the nine colonies to independently confirm the genotype annotations. In all nine colonies, the maternally and paternally transmitted alleles could be unambiguously distinguished. The probability of not detecting identical genotypes of two different fathers $\left(d_{\mathrm{p}}\right)$ was calculated with $d_{\mathrm{p}}=\prod\left(\sum q_{i}^{2}\right)$, where $q_{i}$ is the frequency of the $i$ th allele, with summation over all alleles at a locus and multiplication over all loci (Boomsma and Ratnieks 1996). In case of more than one mating of a given queen, the effective queenmating frequency $\left(k_{E}\right)$ was calculated according to Starr $(1979,1984)$, taking into account the proportion of workers fathered by each male. The intracolonial relatedness $\left(g_{\mathrm{ww}}\right)$ between the workers was calculated according to Crozier and Pamilo (1996) assuming that males were unrelated to queens.

\section{RESULTS}

\subsection{Population genetic parameters}

The analysed loci were highly variable resulting in observed heterozygosities $\left(H_{\mathrm{o}}\right)$ ranging from 0.89 to 1 (Table I). There was no significant deviation from HWE (global test, $P=$ $0.97)$ and no linkage disequilibrium among the tested loci $(P>0.09)$. The non-detection error was $d_{\mathrm{p}}=3.6 \times 10^{-4}$ based on the parental generation's allele frequencies.

\subsection{Observed and effective queen-mating frequency}

From 216 genotyped workers, $204\left(n_{\mathrm{w}}\right.$, Table II) were used to determine the number of observed matings, the effective queen-mating frequency $\left(k_{\mathrm{E}}\right)$ and the intracolonial relatedness for each colony (Table II). Genotyping completely failed for nine workers and three were identified as alien workers from a different colony, having no alleles in common with the mother queen. Colonies $\mathrm{C} 2$ and $\mathrm{C} 4$ were headed by doubly mated queens, whereas all others were headed by singly mated queens, resulting in an average mating frequency of $1.22 \pm 0.44$. The deduced number of matings in all nine colonies was confirmed by using the software MATESOFT 1.0 (Moilanen et al. 2004). In colonies with doubly mated queens, the patrilines were not evenly distributed with the dominant male siring $71 \%$ or $82 \%$, respectively. This paternity skew was significant for colony C2 $\left(\chi^{2}=4.96 ; P=0.03\right)$. In both cases, the effective mating frequency $\left(k_{\mathrm{E}}\right)$ was less than two (Table II) with an average effective mating frequency of $1.12 \pm 0.25$. The intracolonial relatedness $\left(g_{\mathrm{ww}}\right)$ among the workers inferred from the parental generation ranged from 0.54 to 0.75 with a mean of $0.71 \pm 0.08$ (Table II).

Table I. Given are the number of alleles $(A n)$, range and size of the microsatellite fragments in bp, and observed heterozygosity $\left(H_{\mathrm{o}}\right)$ as well as expected heterozygosity $\left(H_{\mathrm{e}}\right)$ per locus and population for all nine $B$. wilmattae colonies.

\begin{tabular}{lllllll}
\hline & B100 & B124 & B126 & B131 & B132 & Population \\
\hline$A n$ & 11 & 6 & 8 & 8 & 4 & 37 \\
Range & $156-192$ & $254-274$ & $150-166$ & $118-146$ & $158-174$ & $118-274$ \\
$H_{\mathrm{o}}$ & 1.00 & 0.89 & 1.00 & 1.00 & 1.00 & $0.98 \pm 0.02$ \\
$H_{\mathrm{e}}$ & 0.92 & 0.72 & 0.83 & 0.86 & 0.71 & $0.81 \pm 0.04$ \\
\hline
\end{tabular}


Table II. Given is the number of observed matings $\left(m_{\text {obs}}\right)$, effective mating frequency $\left(k_{\mathrm{E}}\right)$, intracolonial relatedness $\left(g_{\mathrm{ww}}\right)$ and number of analysed workers $\left(n_{\mathrm{W}}\right)$ of the nine colonies of $B$. wilmattae.

\begin{tabular}{lclll}
\hline Colonies & $m_{\mathrm{obs}}$ & $k_{\mathrm{E}}$ & $g_{\mathrm{ww}}$ & $n_{\mathrm{W}}$ \\
\hline $\mathrm{C} 1$ & 1 & 1.00 & 0.75 & 23 \\
$\mathrm{C} 2$ & 2 & 1.34 & 0.62 & 22 \\
$\mathrm{C} 3$ & 1 & 1.00 & 0.75 & 24 \\
$\mathrm{C} 4$ & 2 & 1.70 & 0.54 & 24 \\
$\mathrm{C} 5$ & 1 & 1.00 & 0.75 & 23 \\
$\mathrm{C} 6$ & 1 & 1.00 & 0.75 & 24 \\
$\mathrm{C} 7$ & 1 & 1.00 & 0.75 & 23 \\
$\mathrm{C} 8$ & 1 & 1.00 & 0.75 & 21 \\
$\mathrm{C} 9$ & 1 & 1.00 & 0.75 & 20 \\
\hline
\end{tabular}

\section{DISCUSSION}

Our results suggest that the neotropical bumblebee, $B$. wilmattae, is predominantly a monandrous species, with seven out of nine analysed colonies being headed by a singly mated queen. However, in two of the analysed colonies, we found offspring of two males showing that also double mating occurs, albeit at a lower frequency. The mating frequency estimates can be considered highly reliable, since the non-detection error was very low due to the highly variable markers. Also the sample size of at least 20 workers per colony is sufficiently large to detect potential additional patrilines unless these are very rare and genetically marginally represented in the colony. The results are in accordance with the mating frequencies determined for the majority of bumblebee species from temperate regions (Estoup et al. 1995; Schmid-Hempel and Schmid-Hempel 2000; Paxton et al. 2001; Sauter et al. 2001; Payne et al. 2003; Takahashi et al. 2008a, b; Kokuvo et al. 2009). Although the analysis of our $B$. wilmattae samples reveals two double-mated colonies, the effective queenmating frequency in these colonies was lower than two, as one father sired the majority of worker offspring. The pattern is very similar to that found in Swiss populations of B. hypnorum where the majority of queens are also single mated and only few double matings occur (Schmid-Hempel and Schmid-Hempel 2000). Interestingly, in this particular species, there seems to be considerable geographical variation in mating frequency, since in Swedish B. hypnorum populations, queens mated up to six times (Paxton et al. 2001). As in our study, in both Swiss and Swedish populations of B. hypnorum, the effective mating frequency in the multiplemated queens was always lower than the observed mating frequency due to the unequal contribution of the males.

Studies on the mating frequency and behaviour of tropical Bombus species are scarce so far and based on behavioural observations solely. In B. atratus, for example, a species which like B. wilmattae is also found in tropical highland rainforests, Garofalo et al. (1986) described up to three matings per queen. However, because they were carried out under laboratory conditions, it is uncertain if these observations are also valid in the wild. Towards the equator, parasite pressure and parasite load show a distinctive cline, with tropical regions having the highest parasite pressure, a correlation which was found for numerous species from several taxa (Poulin and Rohde 1997; Moller 1998; Cumming 2000; Poulin and Morand 2004; Nunn and Altizer 2005). Given also that tropical bumblebees are exposed to more parasites, they might have evolved some form of adaptation towards a higher parasite pressure. Baer and Schmid-Hempel (1999, 2001) artificially inseminated B. terrestris queens with semen from a varying number of males and could show that colonies with a higher intracolonial genetic variability had also a lower parasite load. In spite of the potentially enhanced parasite pressure on bumblebees in the tropics, $B$. wilmattae did not evolve towards polyandry and increased intracolonial genetic variability. Monandry seems to be the common mating pattern in this species and B. wilmattae may have evolved other ways to cope with the higher parasite load typical for the tropics. In any case, our results show that high degrees of polyandry as in B. hypnorum remain the exception rather than the rule in bumblebee mating biology. 


\section{ACKNOWLEDGEMENTS}

We would like to thank Petra Leibe for her assistance in the lab and Daniel Sánchez Guillén for his help and support during the sampling in Chiapas (Mexico). This study was funded by the Helmholtz Interdisciplinary Graduate School for Environmental Research (HIGRADE) and the Mexican-European FONCICYT 94293 grant "MUTUAL-Mutualisms with bees in tropical landscapes: risks and rescue for biodiversity and crop production" which are acknowledged here.

Fréquence d'accouplement et structure génétique des colonies chez le bourdon néotropical Bombus wilmattae (Hymenoptera: Apidae)

\section{Bombus wilmattae / insectes sociaux / fréquence d'accouplement / microsatellites / Mexique}

\section{Paarungsfrequenz und genetische Koloniestruktur der neotropischen Hummel Bombus wilmattae (Hymenoptera: Apidae)}

Bombus wilmattae / Hummeln / eusoziale Hymenopteren / Paarungsfrequenz / Mikrosatelliten.

\section{REFERENCES}

Baer, B., Schmid-Hempel, P. (1999) Experimental variation in polyandry affects parasite loads and fitness in a bumble-bee. Nature 397, 151-154

Baer, B., Schmid-Hempel, P. (2001) Unexpected consequences of polyandry for parasitism and fitness in the bumblebee Bombus terrestris. Evolution 55, 1639-1643

Boomsma, J.J., Ratnieks, F.L.W. (1996) Paternity in eusocial Hymenoptera. Phil. Trans. R. Soc. Lond. B 351, 947-975

Crozier, R.H., Pamilo, P. (1996) Evolution of social insect colonies. Sex allocation and kin selection. Oxford University Press, Oxford

Cumming, G.S. (2000) Using habitat models to map diversity: pan-African species richness of ticks (Acari: Ixodida). J. Biogeogr. 27, 425-440

Estoup, A., Solignac, M., Harry, M., Cornuet, J.M. (1993) Characterization of (Gt)N and (Ct)N microsatellites in 2 insect species-Apis mellifera and Bombus terrestris. Nucleic Acids Res. 21, 1427-1431

Estoup, A., Scholl, A., Pouvreau, A., Solignac, M. (1995) Monoandry and polyandry in bumble bees (Hymenoptera-Bombinae) as evidenced by highly variable microsatellites. Mol. Ecol. 4, 8993

Foster, K.R., Ratnieks, F.L.W. (2001) Convergent evolution of worker policing by egg eating in the honeybee and common wasp. Proc. R. Soc. Lond. B 268, 169-174

Garofalo, C.A., Zucchi, R., Muccillo, G. (1986) Reproductive studies of a neotropical bumblebee, Bombus atratus (Hymenoptera, Apidae). Bras. J. Genet. 9, 231-243

Hamilton, W.D. (1964a) The genetical theory of the evolution of social behaviour. J. Theor. Biol. 7, 1-16

Hamilton, W.D. (1964b) The genetical theory of the evolution of social behaviour. J. Theor. Biol. 7, $17-52$

Hines, H.M., Cameron, S.A., Williams, P.H. (2006) Molecular phylogeny of the bumble bee subgenus Pyrobombus (Hymenoptera: Apidae: Bombus) with insights into gene utility for lower-level analysis. Invertebr. Syst. 20, 289-303

Holehouse, K.A., Hammond, R.L., Bourke, A.F.G. (2003) Non-lethal sampling of DNA from bumble bees for conservation genetics. Insectes Soc. 50, 277-285

Keller, L., Reeve, H.K. (1994) Genetic variability, queen number, and polyandry in social Hymenoptera. Evolution 48, 694-704

Kokuvo, N., Toquenaga, Y., Goka, K. (2009) Effective paternity in natural colonies of Japanese native bumble bees. Ecol. Res. 24, 1111-1115

Labougle, J.M. (1990) Bombus of Mexico and Central America (Hymenoptera, Apidae). Univ. Kansas Sci. Bull. 54, 35-73

Mattila, H.R., Seeley, T.D. (2007) Genetic diversity in honeybee colonies enhances productivity and fitness. Science 317, 362-364

Michener, C.D., LaBerge, W.E. (1954) A large Bombus nest from Mexico. Psyche 61, 63-67

Moilanen, A., Sundström, L., Pedersen, J.S. (2004) MATESOFT: a program for deducing parental genotypes and estimating mating system statistics in haplodiploid species. Mol Ecol Notes 4, 795-797

Moller, A.P. (1998) Evidence of larger impact of parasites on hosts in the tropics: investment in immune function within and outside the tropics. Oikos 82, 265-270

Moritz, R.F.A., Kryger, P., Koeniger, G., Koeniger, N., Estoup, A., Tingek, S. (1995) High-degree of polyandry in Apis dorsata queens detected by DNA microsatellite variability. Behav. Ecol. Sociobiol. 37, 357-363

Nunn, C.L., Altizer, S.M. (2005) The global mammal parasite database: an online resource for infectious disease records in wild primates. Evol. Anthropol. $14,1-2$ 
Park S.D.E. (2001) Trypanotolerance in West African Cattle and the population genetic effects of selection, University of Dublin.

Paxton, R.J., Thoren, P.A., Estoup, A., Tengo, J. (2001) Queen-worker conflict over male production and the sex ratio in a facultatively polyandrous bumblebee, Bombus hypnorum: the consequences of nest usurpation. Mol. Ecol. 10, 2489-2498

Payne, C.M., Laverty, T.M., Lachance, M.A. (2003) The frequency of multiple paternity in bumblebee (Bombus) colonies based on microsatellite DNA at the B10 locus. Insectes Soc. 50, 375-378

Plath, O.E. (1934) Bumblebees and their ways. The Macmillan Company, New York

Poulin R., Morand S. (2004) Parasite biodiversity, Smithson. Inst. Press, Washington D.C.

Poulin, R., Rohde, K. (1997) Comparing the richness of metazoan ectoparasite communities of marine fishes: controlling for host phylogeny. Oecologia 110, 278-283

Raymond, M., Rousset, F. (1995) Genepop (version-1.2): population genetics software for exact tests and ecumenicism. J. Hered. 86, 248-249

Röseler, P. (1973) Die Anzahl der Spermien im Receptaculum Seminis von Hummelköniginnen (Hym., Apoidea, Bombinae). Apidologie 4, 267-274

Sauter, A., Brown, M.J.F., Baer, B., Schmid-Hempel, P. (2001) Males of social insects can prevent queens from multiple mating. Proc. R. Soc. Lond. B 268, 1449-1454

Schmid-Hempel, R., Schmid-Hempel, P. (2000) Female mating frequencies in Bombus spp. from Central Europe. Insect. Soc. 47, 36-41

Sherman, P.W., Seeley, T.D., Reeve, H.K. (1988) Parasites, pathogens, and polyandry in social Hymenoptera. Am. Nat. 131, 602-610
Sladen, F.W.L. (1912) The humble-bee, its life-history and how to domesticate it. Macmillan and Company, London

Starr, C.K. (1979) Origin and evolution of insect sociality: a review of modern theory. In: Hermann, H.R. (ed.) Social Insects, pp. 35-79. Academic, New York

Starr, C.K. (1984) Sperm competition, kinship, and sociality in the aculeate Hymenoptera. In: Smith, R.L. (ed.) Sperm competition and the evolution of animal mating systems, pp. 427-464. Academic, Orlando

Stolle, E., Rohde, M., Vautrin, D., Solignac, M., SchmidHempel, P., Schmid-Hempel, R., Moritz, R.F.A. (2009) Novel microsatellite DNA loci for Bombus terrestris (Linnaeus, 1758). Mol. Ecol. Resour. 9, 1345-1352

Strassmann, J. (2001) The rarity of multiple mating by females in the social Hymenoptera. Insectes Soc. 48, $1-13$

Takahashi, J., Ayabe, T., Mitsuhata, M., Shimizu, I., Ono, M. (2008a) Diploid male production in a rare and locally distributed bumblebee, Bombus florilegus (Hymenoptera, Apidae). Insectes Soc. 55, 43-50

Takahashi, J., Itoh, M., Shimizu, I., Ono, M. (2008b) Male parentage and queen mating frequency in the bumblebee Bombus ignitus (Hymenoptera: Bombinae). Ecol. Res. 23, 937-942

Walsh, P.S., Metzger, D.A., Higuchi, R. (1991) Chelex100 as a medium for simple extraction of DNA for PCR-based typing from forensic material. Biotechniques 10, 506-513

Williams, P.H. (1998) An annotated checklist of bumble bees with an analysis of patterns of description (Hymenoptera: Apidae, Bombini). Bull. Br. Mus. Nat. Hist. (Ent.) 67, 79-152 